\title{
Laminated graphene oxide membrane for recovery of mercury-containing wastewater by pervaporation
}

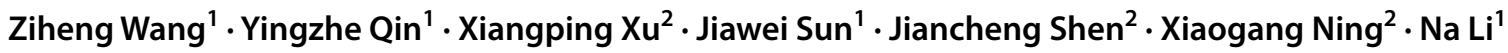

Received: 1 March 2021 / Accepted: 15 June 2021 / Published online: 29 June 2021

(c) The Author(s) 2021

\begin{abstract}
Mercury $(\mathrm{Hg})$ is a toxic heavy metal contaminant and has very harmful effects for human health. In this work, Hg-containing wastewater with $\mathrm{Hg}$ concentration of $6.36 \mathrm{ppb}$ and $9.4 \mathrm{ppb}$ were recovered with polyethylenimine (PEI) cross-linked graphene oxide (GO) layered membrane (c-GO-PEI) by pervaporation. The influence of ionic type, the concentration of $\mathrm{Hg}$ and the feed temperature were investigated. The c-GO-PEI exhibited not only high rejection for salts (>99.97\%), $\mathrm{Hg}(77.5-100 \%)$ and non-purgeable organic carbon (NPOC) $(67.3-90.8 \%)$ but also high flux $\left(30.30 \mathrm{~kg} \cdot \mathrm{m}^{-2} \cdot \mathrm{h}^{-1}\right)$ to treat with the wastewater. In addition, the flux could be largely recovered after simple washing, indicating the excellent antifouling property of the membrane.
\end{abstract}

Keywords Laminated graphene oxide membrane $\cdot$ Wastewater treatment $\cdot$ Mercury removal $\cdot$ Pervaporation

\section{Introduction}

With the development of industrialization and urbanization, water pollution is a major concern, and the efficient treatment of wastewater is becoming a challenge. In carbonaceous fuel combustion and petrochemical industry, a large amount mercury-containing waste gas and wastewater are produced. As a toxic heavy metal, mercury $(\mathrm{Hg})$ can accumulate in food chain and has long-term influence on human beings, especially the nervous system.(Yu et al. 2016) Thus, attentions should be paid to the treatment of $\mathrm{Hg}$-containing wastewater. Recently, various $\mathrm{Hg}$ removal approaches have been developed, such as chemical precipitation, adsorption, ion exchange and membrane separation. (Azimi et al. 2017; Oehmen et al. 2014; Yu et al. 2016) However, chemical precipitation causes second pollution.

Jiancheng Shen

737118508@qq.com

$\triangle \mathrm{NaLi}$

lina@mail.xjtu.edu.cn

1 Shaanxi Key Laboratory of Energy Chemical Process Intensification, School of Chemical Engineering and Technology, Xi' an Jiaotong University, Xi' an 710049, Shaanxi, People's Republic of China

2 Shaanxi Beiyuan Chemical Group Co., Ltd, Yulin 719319 , Shaanxi, People's Republic of China
Adsorption faces the problem of ion competition. And ion exchange produces reclaimed water. Membrane separation is widely used in wastewater treatment with the advantages of low energy consumption, no chemical additives and ready coupling with other processes.(Pendergast and Hoek 2011; Samsami et al. 2020) Ultrafiltration (UF) and nanofiltration (NF) are widely employed in wastewater treatment. However, UF cannot reject small molecules and ions including $\mathrm{Hg}^{2+}$ because of the porous nature of UF membranes. As a pressure-driven processes, nanofiltration (NF) will face the problems of serious membrane fouling and concentration polarization when treating complex wastewater. (Kim, 2018) Moreover, the evaporation-crystallization process that has been widely used for salty water treatment is hard to attain $\mathrm{Hg}$-free distillate due to the volatility of $\mathrm{Hg}$. (Bin et al. 2019)

Pervaporation is a membrane-based separation method, in which the feed solution flow through the upside of the membrane and become vapor in the downside. The membrane structure could be well-tuned to make it be capable of rejecting salts(Castro-Munoz 2020; Wang et al. 2016a) and volatile components(Cao et al. 2021; Ong et al. 2016; Yang, 2019). Besides, low membrane fouling could be achieved by reducing the roughness and elevating the hydrophilicity of the membrane surface. These properties make pervaporation a promising method to treat wastewater with multiple components and obtain fresh water. Recently, wastewater treatment by pervaporation has been widely studied, aiming 
to remove or recover organic compounds(Aliabadi et al. 2011, 2012; Cao et al. 2021; García et al. 2013; Kujawa et al. 2015; Li et al. 2018; Mei, 2020; Toth and Mizsey 2015; Wang et al. 2018; Wu et al. 2016; Yi and Wan 2017; Zhang et al. 2016; Zhao and Shi 2009), sulfuric acid(Cui et al. 2020; Liu et al. 2021), ammonia(Yang, 2014) and heavy metals(Baysak 2021; Nigiz 2019). Baysak (Baysak 2021) fabricated polyvinyl alcohol/NaY zeolite membranes to recover $\mathrm{Cr}$ from wastewater by pervaporation, and results showed that the membrane could effectively reject $\mathrm{Cr}(\mathrm{VI})$. Nigiz (Nigiz 2019) prepared poly(vinyl alcohol) membranes coated with poly(ether-block-amide) layer and investigated pervaporation desalination performance treating seawater containing lithium, copper, arsenic and lead. The composite membranes exhibited heavy metal rejections $>94 \%$. As far as we known, the recovery of $\mathrm{Hg}$ by pervaporation has not yet been reported.

Recently, various materials were developed to construct pervaporation membranes, in which graphene oxide (GO) has promising prospects. GO was composed of two-dimensional hexagonal skeleton of carbon atom structure and oxygen groups, which has the properties of high strength, hydrophilicity and easy to modify. By means of filtration, coating or layer-by-layer deposition(Wei et al. 2018), GO nano flakes could be self-assembled on the substrate, forming an ultrathin dense membrane of layered structure. However, pure GO membranes are prone to swell and collapse in water condition. To strengthen the structural stability of GO membranes, a large amount of cross-linking agents were applied, including polymers(Chen et al. 2014; Cheng et al. 2017; Pan, 2020; Park et al. 2009; Suri et al. 2019; Tian et al. 2013), small molecules(An et al. 2011; Feng et al. 2016; Hung, 2014; Jia et al. 2016; Liu et al. 2020; Qian et al. 2018; Wang, 2016b; Zhang et al. 2020, 2015), ions(Chen, 2017; Gao et al. 2019; Lin and Chen 2021; Park et al. 2008; Yu et al. 2017) and nano materials(Cho, 2019; Dong et al. 2020; Shi, 2019; Xi et al. 2016). Polyethylenimine (PEI) is a kind of hydrophilic and flexible polymer, and abundant amino group endows PEI molecules with positive charge. GO was negatively charged by carboxyl group, which could react with amino group, resulting in a favorable cross-linking structure based on both electrostatic attraction and covalent bonding. The structure is hoped to improve the mechanical strength of the GO layered membrane. Besides, with PEI intercalation, the zeta potential of GO-PEI membranes could be converted to positive, and the membranes are able to reject cations (e.g., $\mathrm{Hg}^{2+}$ ) by electrostatic repulsion.

Herein, PEI intercalated GO layered membrane was fabricated with pressure-assisted self-assembly method and cross-linked in acid environment. The morphology, chemical composition and hydrophilicity were investigated. The prepared membrane was applied to treat $\mathrm{Hg}$-containing wastewater by pervaporation. This work enlightens a new way to develop membranes for complex wastewater treatment, especially removal or recovery of volatile components.

\section{Experimental}

\section{Materials}

Graphite was purchased from Tianjin No. 1 Chemical Reagent Factory, China. Potassium permanganate $\left(\mathrm{KMnO}_{4}\right)$, sodium nitrate $\left(\mathrm{NaNO}_{3}\right)$, sulfuric acid $\left(\mathrm{H}_{2} \mathrm{SO}_{4}\right)$ and hydrochloric acid $(\mathrm{HCl})$ were purchased from Xi Long Chemical Co., Ltd., China. Hydrogen peroxide $\left(\mathrm{H}_{2} \mathrm{O}_{2}\right)$ and sodium chloride $(\mathrm{NaCl})$ were supplied by Sinopharm Chemical Reagent Co., Ltd., China. Polyethylenimine (PEI) with molecular weight of 70000 was purchased from Shanghai Aladdin Biochemical Technology Co., Ltd. All materials and reagents were used without further treatment. Deionized (DI) water was self-made in laboratory. Mixed cellulose ester (MCE) microfiltration membranes (diameter of $80 \mathrm{~mm}$ and pore size of $0.22 \mu \mathrm{m}$ ) were purchased from Chuangwei Filter Equipment. Hg-containing wastewater was provided by Shaanxi Beiyuan Chemical Group Co., Ltd, China.

\section{Preparation of GO}

GO was synthesized by Hummers method. First, $6 \mathrm{~g}$ graphite powder, $3 \mathrm{~g} \mathrm{NaNO}_{3}$ and $138 \mathrm{~mL} \mathrm{H}_{2} \mathrm{SO}_{4}$ were mixed together under continuous stirring and $30 \mathrm{~g} \mathrm{KMnO}_{4}$ was slowly added. The reaction was kept at $0{ }^{\circ} \mathrm{C}$ for $2 \mathrm{~h}$ and for another $5 \mathrm{~h}$ at $35^{\circ} \mathrm{C}$. Then, $276 \mathrm{~mL}$ DI water was progressively added into the mixture and the temperature was raised to $95{ }^{\circ} \mathrm{C}$ and kept for $30 \mathrm{~min}$. After the mixture was cooled to room temperature, $840 \mathrm{~mL}$ DI water and $60 \mathrm{~mL}$ $\mathrm{H}_{2} \mathrm{O}_{2}$ were added. The mixture was repeatedly washed with $3 \% \mathrm{HCl}$ and DI water till neutral $\mathrm{pH}$ was achieved and then centrifuged at $8000 \mathrm{rpm}$ to remove the supernatant. Finally, the sediment was dried at $50{ }^{\circ} \mathrm{C}$ in a vacuum oven and the GO was obtained.

\section{Preparation of c-GO-PEI membranes}

Pressure-assisted self-assembly method was used to fabricate GO membranes. First, GO was dispersed in DI water by sonication to form an aqueous dispersion of $0.5 \mathrm{~g} / \mathrm{L}$. PEI was dissolved in DI water at $0.5 \mathrm{~g} / \mathrm{L}$. Then, $2 \mathrm{~mL}$ GO dispersion and $10 \mathrm{~mL}$ PEI solution were added into $200 \mathrm{~mL}$ DI water under stirring. The mixture was filtrated through nylon microfiltration substrate membrane and after filtration, the membrane was dried in a hot air oven at $50{ }^{\circ} \mathrm{C}$ for $4 \mathrm{~h}$. Subsequently, the GO-PEI membrane was soaked in DI water at room temperature for $12 \mathrm{~h}$ and then in a mixture of $200 \mathrm{~mL}$ DI water and $2 \mathrm{~mL} \mathrm{HCl}$ for reaction at $50{ }^{\circ} \mathrm{C}$ for $4 \mathrm{~h}$. After 
that, the membranes were dried in a hot air oven at $50{ }^{\circ} \mathrm{C}$ for $4 \mathrm{~h}$. The prepared membrane was denoted as c-GO-PEI.

\section{Characterizations}

Chemical composition of membranes was analyzed by Fourier transform infrared spectroscopy with attenuated total reflectance mode (ATR-FTIR, Thermo Fisher Scientific, Nicolet iS50) and X-ray photoelectron spectroscopy (XPS, Thermo Fisher Scientific, ESCALAB Xi +). Surface hydrophilicity was measured by water contact angle (WCA, KRÜSS, DSA100). Surface morphology was obtained with scanning electronic microscope (SEM, TESCAN, MAIA3LMH). Element distribution of membranes was analyzed by energy dispersive X-ray spectrometry (EDS, Aztec X-maxN50) on SEM. Electrokinetic analyzer (Anton Paar, SurPASS) was used to measure the zeta potential of membrane surface.

\section{Pervaporation performance of GO-PEI membranes}

The pervaporation performance of c-GO-PEI membranes was tested with a home-made instrument, as illustrated in Fig. 1. The effective membrane area is $15.9 \mathrm{~cm}^{2}$. During the test, feed solution was heated by water bath and circulated from feed tank to the membrane surface and back to the feed tank with a peristaltic pump at flow rate of $18 \mathrm{~L} / \mathrm{h}$. The permeate was condensed with liquid nitrogen and collected with a cold trap at vacuum of $0.096 \mathrm{MPa}$. The flux $\left(J, \mathrm{~kg} \cdot \mathrm{m}^{-2} \cdot \mathrm{h}^{-1}\right)$ and rejection $(R, \%)$ were calculated with following equations.
$J=\frac{W}{A \cdot t}$

where $W(\mathrm{~kg})$ is the weight loss of feed solution during the test, $A\left(\mathrm{~m}^{2}\right)$ is the effective membrane area, and $t(\mathrm{~h})$ is the time of the pervaporation test.

$R=\frac{c_{f}-c_{p}}{c_{f}} \times 100 \%$

where $c_{f}$ and $c_{p}$ are the concentration of feed and permeate solutions, respectively.

\section{Characterization}

The surface images of GO and c-GO-PEI membranes were shown in Fig. 2a and b. The top layer on the MCE support is dense and demonstrates typical wrinkles of GO nanosheets. With intercalation of PEI, the wrinkles of c-GO-PEI became flatter and broader. This should be related to the interaction of the long PEI chains with GO nanosheets that could induce the spreading and flattening of GO sheets in the assembly of laminated structure. In cross-sectional view (Fig. 2c, d), it is observed that GO layers closely stacked on the substrate with a thickness of $100 \mathrm{~nm}$ and $270 \mathrm{~nm}$ for GO and c-GOPEI membranes, respectively. The increased thickness is resultant from enlarged interlayer spacing of GO nanosheet by the intercalation of PEI. The thicker layer could also diminish the effect of coarse structure of MCE support on the morphology of the thin GO layer. The smoothed membrane surface is expected to be favorable in reducing membrane fouling.

Figure 3a shows the ATR-FTIR spectra of GO and c-GO-PEI membranes. The peaks at 3390, 1737, 1459 and $1274 \mathrm{~cm}^{-1}$ represent $-\mathrm{OH}, \mathrm{C}=\mathrm{O}, \mathrm{C}-\mathrm{O}$ and $\mathrm{C}-\mathrm{O}-\mathrm{C}$, respectively, indicating characteristic absorption bands of
Fig. 1 Schematic diagram of pervaporation experiment setup

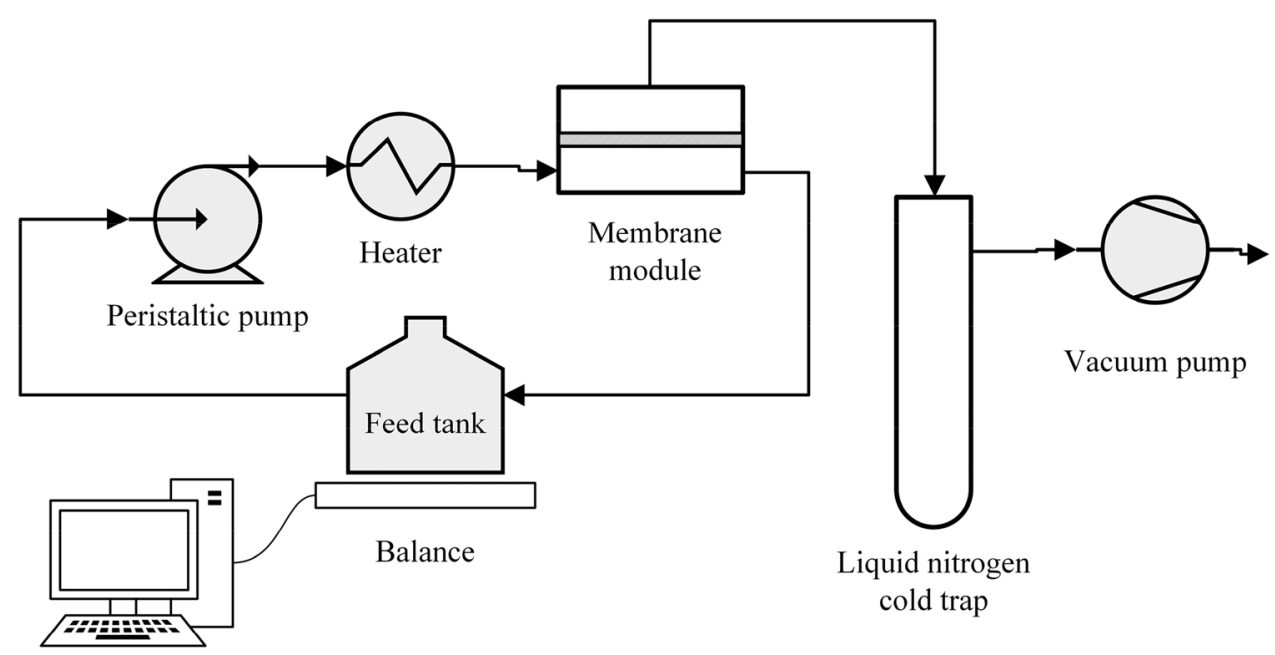

Computer 
Fig. 2 SEM images of pristine GO and c-GO-PEI membranes
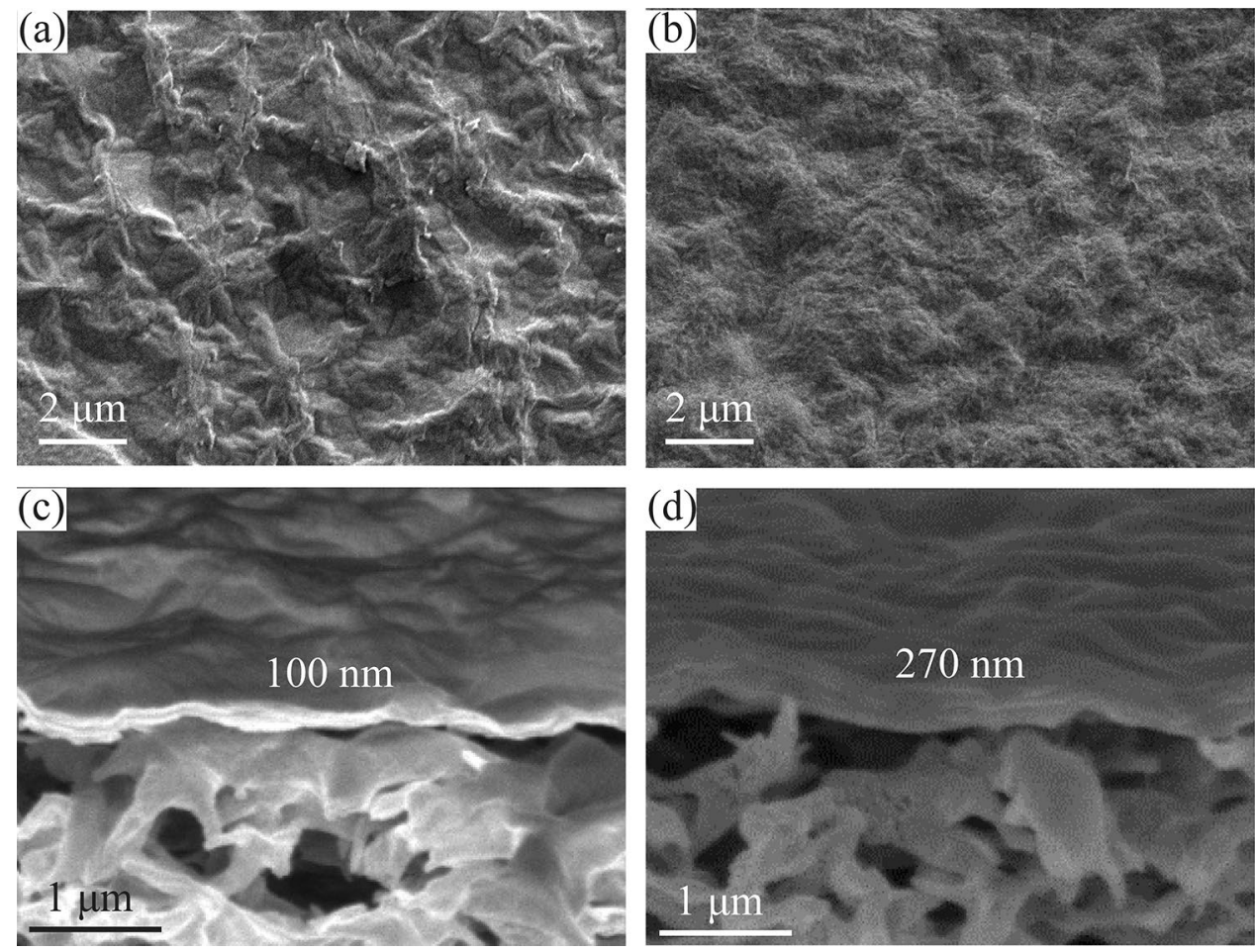

(a)

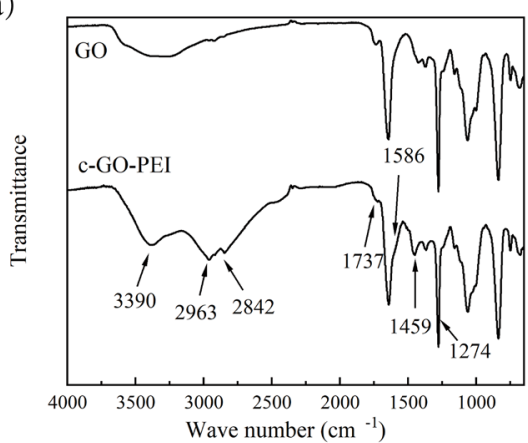

(b)

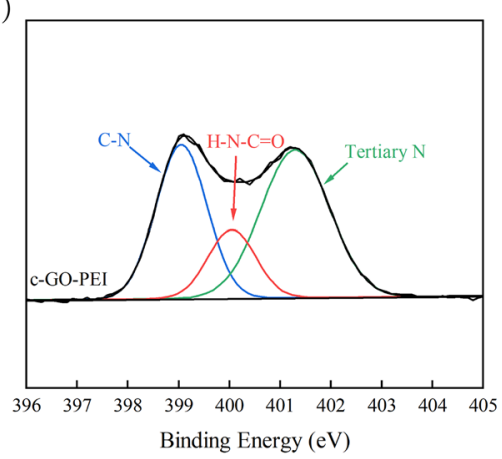

(c)

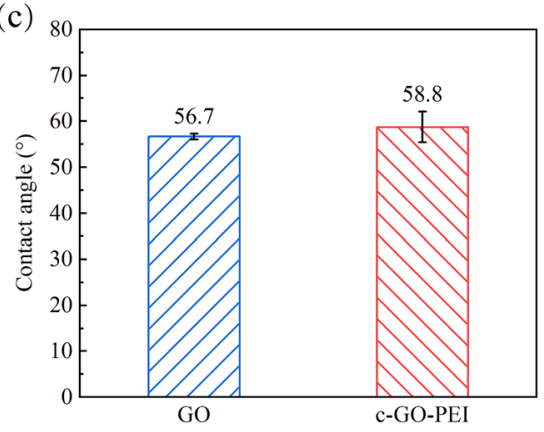

Fig. 3 a FTIR spectra of GO and c-GO-PEI membranes, b XPS N1s fitting curve of c-GO-PEI membrane and $\mathbf{c}$ water contact angles of GO and c-GO-PEI membranes

GO. For the spectrum of c-GO-PEI, characteristic peaks of $\mathrm{N}-\mathrm{H}$ can be seen at $1586 \mathrm{~cm}^{-1}$, and $\mathrm{C}-\mathrm{H}$ can be seen at 2842 and $2963 \mathrm{~cm}^{-1}$, confirming the existence of PEI and the formation of cross-linking structure in the membrane. (Guo et al. 2021; Halakoo and Feng 2020; Qian et al. 2018) In XPS N1s spectrum (Fig. 3b), the fitted peaks represent $\mathrm{C}-\mathrm{N}$ at $399.0 \mathrm{eV}, \mathrm{N}-\mathrm{C}=\mathrm{O}$ at $400.1 \mathrm{eV}$ and tertiary $\mathrm{N}$ at $401.3 \mathrm{eV}$, which confirms the successful intercalation of PEI in the GO membrane. The characteristic $\mathrm{N}-\mathrm{C}=\mathrm{O}$ peak is assigned to the amide bond formed by GO and PEI in crosslinking.(Pan et al. 2020).

The water flux and antifouling performance are affected by membrane surface hydrophilicity. Figure $3 \mathrm{c}$ depicts the water contact angles of GO and c-GO-PEI membranes. The pristine GO membrane exhibits a hydrophilic surface, owing to the existence of abundant oxygen-containing groups on GO. After PEI intercalation and cross-linking, the c-GO-PEI membrane still shows good hydrophilicity with water contact angle slightly increased to $58.8^{\circ}$, which is because of the consumption of oxygen groups in crosslinking.(Sun et al. 2020) In addition, it is measured that the surface zeta potential of GO membrane and c-GO-PEI membrane are $-28.7 \mathrm{mV}$ and $+31.7 \mathrm{mV}$, respectively. The conversion of zeta potential from negative to positive value further indicates the successful hybrid of PEI in GO membrane. 




Fig. 4 PV performance of c-GO-PEI membranes

\section{Pervaporation performance}

\section{Desalination test}

$\mathrm{NaCl}$ and $\mathrm{MgSO}_{4}$ were used as feed solutes to test the PV performance of membrane in treating with different salt ions. As shown in Fig. 4, the salt rejection for $\mathrm{NaCl}$ and mixed ion solution were both $99.99 \%$. Besides the non-volatility of salts, the electrostatic repulsion of positively charged membrane to salt cations should also contribute to the perfect salt rejection. Due to the high salt concentration, the partial vapor pressure of feed reduced; and thus the water flux of salt solutions slightly decreased by $9.4 \%$ and $11.1 \%$ than pure water. Nevertheless, the flux of mixed ion solution is near to that of $\mathrm{NaCl}$ solution, indicating the good desalination performance of the membrane for complex salt solution.

\section{Hg-containing wastewater test}

In chemical industry, Hg-containing wastewater is generally produced due to the employment of $\mathrm{Hg}$-containing catalysts such as for the synthesis of polyvinyl chloride. The traditional evaporation method is limited due to the natural volatility of $\mathrm{Hg}$. Pervaporation could be an effective way to remove trace $\mathrm{Hg}$ because of its potential of rejecting volatile components. The wastewater with two levels of $\mathrm{Hg}$ content, $6.36 \mathrm{ppb}$ and $9.4 \mathrm{ppb}$, was used to test the PV performance of membrane for the remove of $\mathrm{Hg}$ and NPOC. The components of the wastewater are listed in Table 1. Hg exists in the form of $\mathrm{HgCl}_{2}$ molecules and $\mathrm{Hg}$ ions such as $\mathrm{Hg}^{2+}, \mathrm{HgCl}^{+}, \mathrm{HgCl}_{3}{ }^{-}$and $\mathrm{HgCl}_{4}{ }^{2-}$ (Wang et al. 2016c). The $\mathrm{PV}$ performance was shown in Fig. 5. It can be seen that $35 \mathrm{vol} \%$ solution was collected in the permeate after $6 \mathrm{~h}$ of the concentration process, during which the flux gradually decreased because of the decline of water vapor pressure
Table 1 Contents in $\mathrm{Hg}$-containing wastewater

\begin{tabular}{|c|c|c|}
\hline $\mathrm{Hg} / \mathrm{ppb}$ & 6.36 & 9.4 \\
\hline $\mathrm{pH}$ & 8.17 & 8.21 \\
\hline Conductivity $/ \mathrm{mS} \cdot \mathrm{cm}^{-1}$ & 107.1 & 102.6 \\
\hline $\mathrm{NaCl} / \mathrm{mg} \cdot \mathrm{L}^{-1}$ & 7567 & 7248 \\
\hline $\mathrm{Na}_{2} \mathrm{SO}_{4} / \mathrm{mg} \cdot \mathrm{L}^{-1}$ & 1282 & 1228 \\
\hline $\mathrm{NPOC} / \mathrm{mg} \cdot \mathrm{L}^{-1}$ & 71.74 & 74.56 \\
\hline
\end{tabular}

and the inevitably increased concentration polarization while remaining a considerably high level of above $26 \mathrm{~kg} \bullet \mathrm{m}^{-2} \cdot \mathrm{h}^{-1}$ in the end (Fig. 5a). Salt rejection always maintained over 99.97\% (Fig. 5b). The removal rate of $\mathrm{Hg}$ is higher than $90 \%$ in most cases (Fig. 5c). The membrane exhibited good rejection for NOPC component (Fig. 5d) due to the hydrophilicity of membrane which facilitates water permeation while hinders the transport of organic molecules.

Figure 6 shows the effects of feed temperature on the flux and rejection with c-GO-PEI. The flux increases rapidly as temperature increases from 55 to $75^{\circ} \mathrm{C}$, which is because of the rise of water vapor pressure and intensified motion of PEI chains with temperature. The flux with wastewater containing $6.36 \mathrm{ppb} \mathrm{Hg}$ was lower than that containing $9.4 \mathrm{ppb}$ $\mathrm{Hg}$, which is related to the higher salt concentration of the former solution. At the same time, the rejections to salt, $\mathrm{Hg}$ and NPOC remained at high levels, which means c-GO-PEI could perform well at a wide range of temperature. Figure 7 shows that, by the one-step PV process, the clear permeate was obtained from the yellow wastewater samples. All the results indicate the good efficiency of the PV process with c-GO-PEI membrane in the wastewater treatment.

\section{Antifouling test}

To study the fouling and $\mathrm{Hg}$ adsorption of the membranes, after the PV experiment (Fig. 6), the morphology and element distribution of membrane surface was analyzed by SEM and EDS. By EDS analysis, it is found that $\mathrm{Hg}$ mass fraction on membrane are $2.53 \%$ and $2.84 \%$ for c-GO-PEI membranes tested with $6.36 \mathrm{ppb}$ and $9.4 \mathrm{ppb}$ wastewater, respectively, which are lower than $3.84 \%$ for the pristine GO membrane. This should be related to the repulsion capability of positively charged PEI-modified membrane to $\mathrm{Hg}$ in the wastewater. The SEM images (Fig. 8) show less pollutant that adsorbed on the top surface of c-GO-PEI membranes compared to that on the pristine membrane, which confirms the improved antifouling property of the PEI-modified membrane.

Moreover, $\mathrm{Hg}$ adsorption content was estimated by mass balance calculation and illustrated in Table. 2. The




Fig. 5 Pervaporation performance of c-GO-PEI: a Flux, b Salt rejection, $\mathbf{c} \mathrm{Hg}$ rejection, $\mathbf{d}$ NPOC removal rate(Operating temperature: $65^{\circ} \mathrm{C}$ )

Fig. 6 Pervaporation performance of c-GO-PEI at different temperatures: a Flux and salt rejection; $\mathbf{b} \mathrm{Hg}$ and NPOC removal rates

Fig. 7 Photographs of $\mathrm{Hg}$ containing wastewater samples before and after PV treatment. a $6.36 \mathrm{ppb}$ feed solution, PV retentate solution and PV permeate; $\mathbf{b} 9.4 \mathrm{ppb}$ feed solution, $\mathrm{PV}$ retentate solution and PV permeate (from left to right) (a)

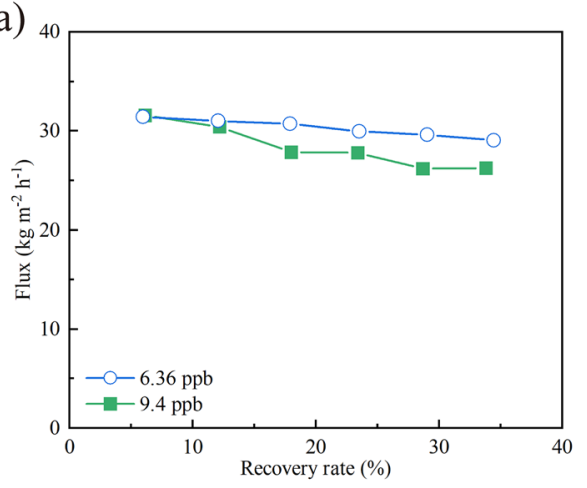

(c)



(a)

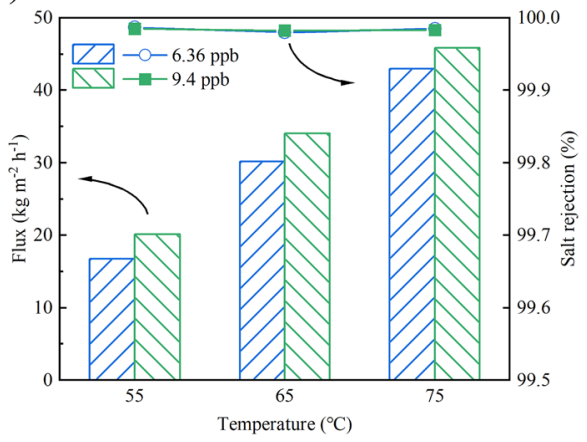

(a)

(b)
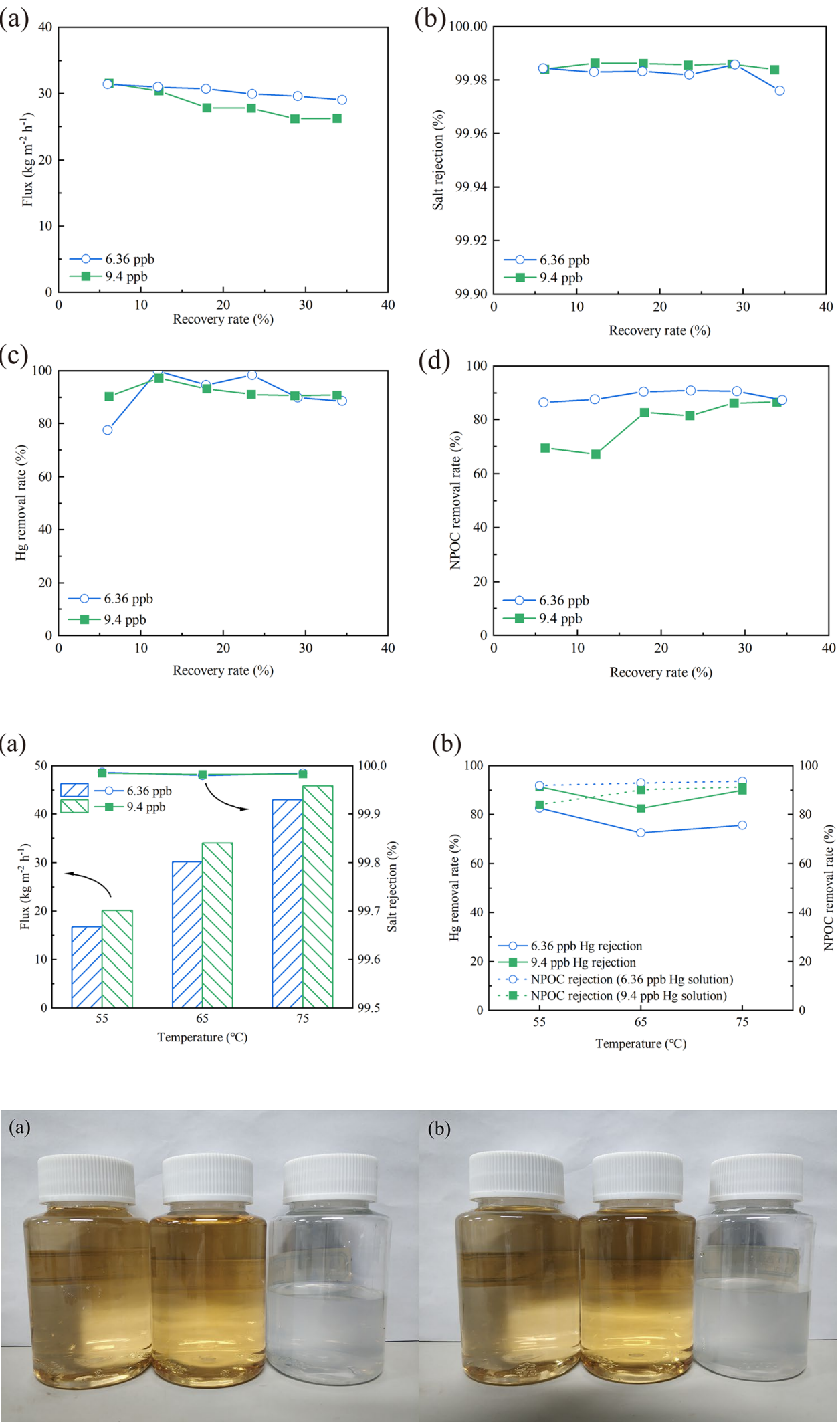

(d)

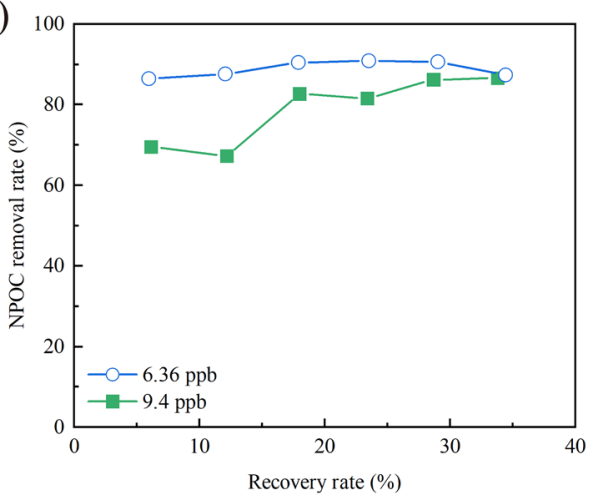

(b)

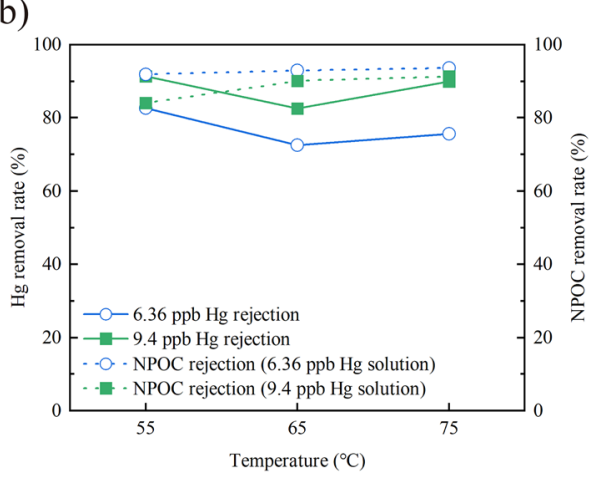

mperature $\left({ }^{\circ} \mathrm{C}\right)$ 

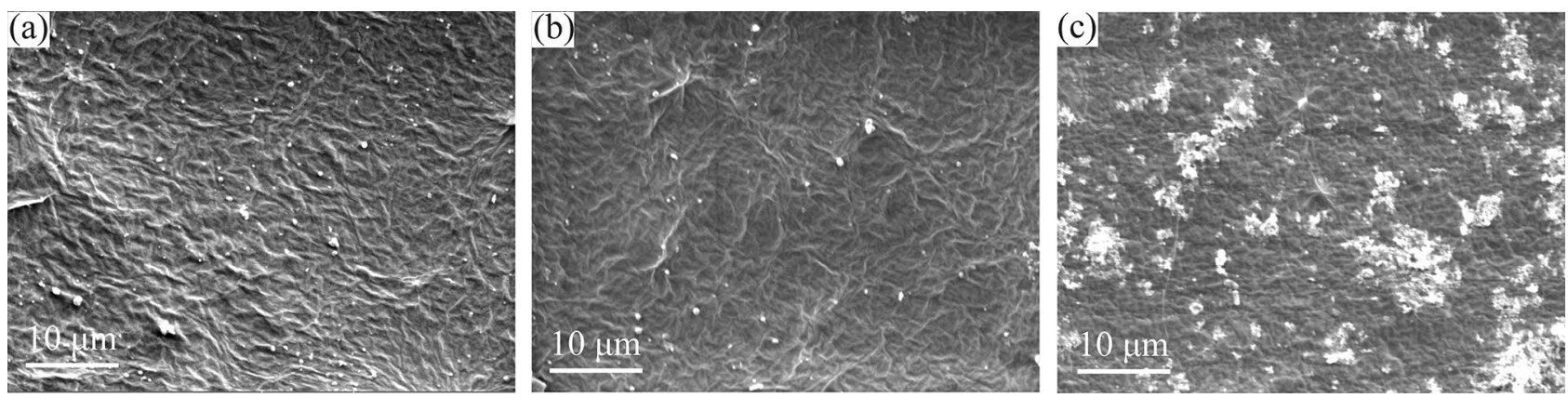

Fig. 8 Surface morphology of membranes after PV test. a c-GO-PEI (6.36 ppb Hg wastewater); b c-GO-PEI (9.4 ppb Hg wastewater); c pristine GO membrane (9.4 ppb Hg wastewater)

Table. 2 Mass balance calculation of $\mathrm{Hg}$-containing wastewater test

\begin{tabular}{lllllll}
\hline $\begin{array}{l}\text { Hg concentration } \\
\text { in feed /ppb }\end{array}$ & Mass of feed /g & $\begin{array}{l}\text { Hg concentration in con- } \\
\text { centrated feed /ppb }\end{array}$ & $\begin{array}{l}\text { Mass of concen- } \\
\text { trated feed /g }\end{array}$ & $\begin{array}{l}\text { Hg concentration in } \\
\text { permeate /ppb }\end{array}$ & $\begin{array}{l}\text { Mass of } \\
\text { permeate /g }\end{array}$ & $\begin{array}{l}\text { Hg content ratio } \\
6.36\end{array}$ \\
\hline 9.4 & 850.9 & 10.46 & 547.7 & 0.54 & 303.2 & 1.09 \\
\hline
\end{tabular}

Fig. 9 Antifouling performance of c-GO-PEI membrane in treating with $\mathrm{Hg}$-containing wastewaters. (a) Flux; (b) Salt rejection and removal rates of NPOC and $\mathrm{Hg}$ (Operating temperature: $65^{\circ} \mathrm{C}$ ) (a)

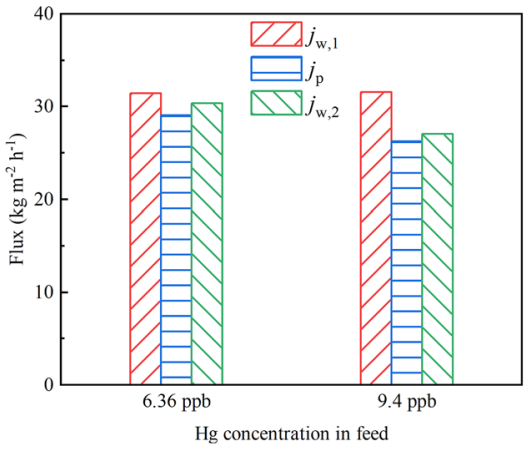

(b)

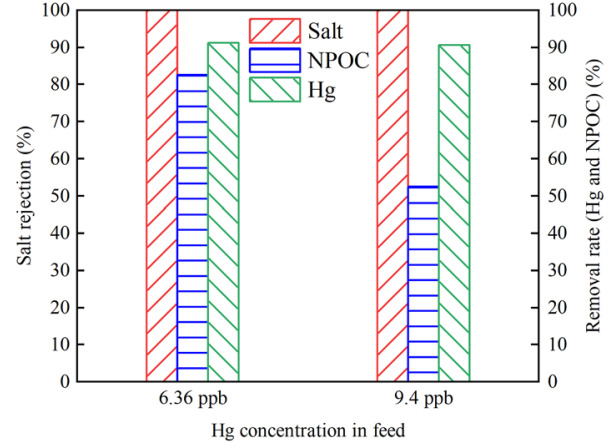

$\mathrm{Hg}$ content ratios are very closed to one, indicating the $\mathrm{Hg}$ adsorption is slight on the membrane during the PV test.

$\mathrm{Hg}$ content ratio $=\frac{\mathrm{Hg} \text { content in concentrated feed }+\mathrm{Hg} \text { content in permeate }}{\mathrm{Hg} \text { content in feed }}$

The antifouling property of membrane was further investigated in terms of flux recovery ratio and fouling ratio. After the $\mathrm{PV}$ concentration test with $\mathrm{Hg}$-containing wastewater for $6 \mathrm{~h}$ (Fig. 5), the membranes were rinsed with $500 \mathrm{~mL}$ DI water for $10 \mathrm{~min}$, which was repeated for three times. After washing, the PV performance of membrane were tested for one hour at $65{ }^{\circ} \mathrm{C}$, after which four parameters are calculated by Eqs. 4-7: FRR (flux recovery ratio), $R_{\mathrm{t}}$ (total fouling ratio), $R_{\mathrm{r}}$ (reversible fouling ratio) and $R_{\mathrm{ir}}$ (irreversible fouling ratio), where $j_{\mathrm{w}, 1}$ and $j_{\mathrm{p}}$ are the fluxes of the first and the last hour in PV concentrating test, and $j_{\mathrm{w}, 2}$ is the flux of the cleaned membrane.
Table 3 Antifouling parameters of c-GO-PEI treating Hg-containing wastewater

\begin{tabular}{llrrr}
\hline $\begin{array}{l}\text { Hg concentration } \\
\text { in feed }\end{array}$ & FRR $(\%)$ & $R_{\mathrm{t}}(\%)$ & $R_{\mathrm{r}}(\%)$ & $R_{\text {ir }}(\%)$ \\
\hline $6.36 \mathrm{ppb}$ & 96.69 & 7.45 & 4.14 & 3.31 \\
$9.4 \mathrm{ppb}$ & 85.72 & 16.81 & 2.53 & 14.28 \\
\hline
\end{tabular}

As shown in Fig. 9a, the fluxes were largely recovered after the simply washing, and the retention to the solutes remained high (Fig. 9b). The results of FRR, $R_{\mathrm{r}}$ and $R_{\mathrm{ir}}$ are listed in Table. 3, which indicate good antifouling property of the membrane. The membrane remained an intact and clear surface after the long-term usage and washing (Fig. 10). The results indicate the reliability of membrane in treating with the wastewater. 


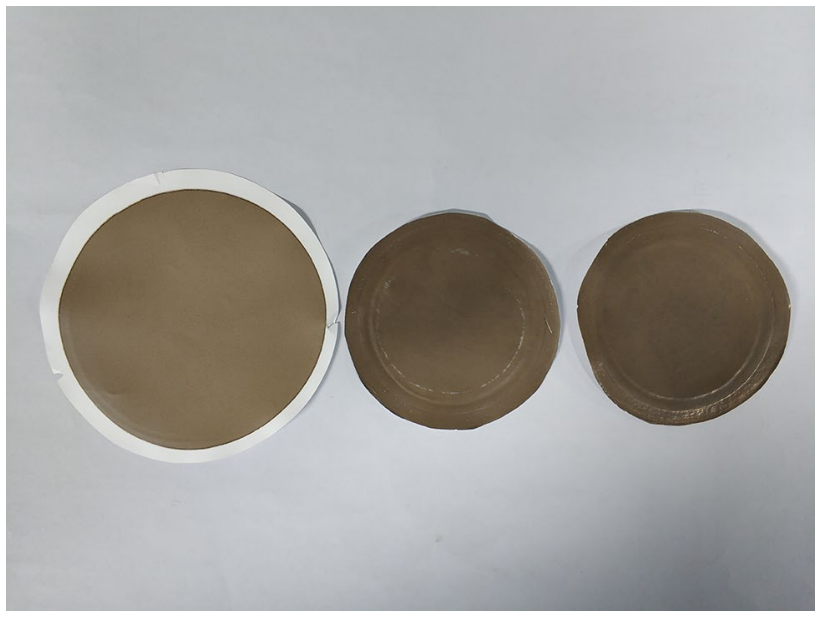

Fig. 10 Digital photographs of c-GO-PEI membranes before (left) and after test with $6.36 \mathrm{ppb}$ (center) and $9.4 \mathrm{ppb}$ (right) Hg-containing wastewaters that washed with DI water

$$
\begin{aligned}
& \text { FRR }=\frac{j_{w, 2}}{j_{w, 1}} \times 100 \% \\
& R_{t}=\frac{j_{w, 1}-j_{p}}{j_{w, 1}} \times 100 \% \\
& R_{r}=\frac{j_{w, 2}-j_{p}}{j_{w, 1}} \times 100 \% \\
& R_{i r}=\frac{j_{w, 1}-j_{w, 2}}{j_{w, 1}} \times 100 \%=R_{t}-R_{r}
\end{aligned}
$$

\section{Conclusion}

In this study, c-GO-PEI membrane was prepared to recover Hg-containing wastewater by pervaporation. The membrane shows high flux and almost all salts and $\mathrm{Hg}$ were rejected by c-GO-PEI attributed to the electrostatic repulsion between ions and the membrane surface. Due to the positively charged, hydrophilic and smooth membrane surface, the flux could be well recovered by simple washing. This work provides a new approach for treating wastewater with salts, heavy metals and organic components.

Acknowledgements We would thank Prof. Youlong $\mathrm{Xu}$ and his students at Xi'an Jiaotong University for their kind help with the measurement of surface zeta potential of membrane.

Funding This work was supported by the National Natural Science Foundation of China (Grant Number 21676210) and the Enterprise Joint Foundation of Shaanxi Science and Technology Department in China (Grant Number 2019JLM-23).

\section{Declarations}

Conflict of interest The authors declare no conflicts of interest to this work.

Ethical approval All the authors have made significant contributions to this work. Informed consent was obtained from all individual participant included in the study.

Open Access This article is licensed under a Creative Commons Attribution 4.0 International License, which permits use, sharing, adaptation, distribution and reproduction in any medium or format, as long as you give appropriate credit to the original author(s) and the source, provide a link to the Creative Commons licence, and indicate if changes were made. The images or other third party material in this article are included in the article's Creative Commons licence, unless indicated otherwise in a credit line to the material. If material is not included in the article's Creative Commons licence and your intended use is not permitted by statutory regulation or exceeds the permitted use, you will need to obtain permission directly from the copyright holder. To view a copy of this licence, visit http://creativecommons.org/licenses/by/4.0/.

\section{References}

Aliabadi M, Aroujalian A, Raisi A (2011) Pervaporative removal of acrylonitrile from aqueous streams through polydimethylsiloxane membrane. Water Sci Technol 63:2820-2826. https://doi.org/10. 2166/wst.2011.612

Aliabadi M, Aroujalian A, Raisi A (2012) Removal of styrene from petrochemical wastewater using pervaporation process. Desalination 284:116-121. https://doi.org/10.1016/j.desal.2011.08.044

An Z, Compton OC, Putz KW, Brinson LC, Nguyen ST (2011) Bioinspired borate cross-linking in ultra-stiff graphene oxide thin films. Adv Mater 23:3842-3846. https://doi.org/10.1002/adma. 201101544

Azimi A, Azari A, Rezakazemi M, Ansarpour M (2017) Removal of heavy metals from industrial wastewaters: a review. Chembioeng Rev 4:37-59. https://doi.org/10.1002/cben.201600010

Baysak FK (2021) A novel approach to Chromium rejection from sewage wastewater by pervaporation. J Mol Struct 1233:130082. https://doi.org/10.1016/j.molstruc.2021.130082

Bin H, Yang Y, Cai L, Yang L, Roszak S (2019) Enhancing mercury removal across air pollution control devices for coal-fired power plants by desulfurization wastewater evaporation. Environ Technol 40:154-162. https://doi.org/10.1080/09593330.2017.1380716

Cao XT, Wang KA, Feng XS (2021) Removal of phenolic contaminants from water by pervaporation. J Membr Sci 623:119043. https:// doi.org/10.1016/j.memsci.2020.119043

Castro-Munoz R (2020) Breakthroughs on tailoring pervaporation membranes for water desalination: a review. Water Res 187:116428. https://doi.org/10.1016/j.watres.2020.116428

Chen L et al (2017) Ion sieving in graphene oxide membranes via cationic control of interlayer spacing. Nature 550:380-383. https:// doi.org/10.1038/nature24044

Chen L, Huang L, Zhu J (2014) Stitching graphene oxide sheets into a membrane at a liquid/liquid interface. Chem Commun (camb) 50:15944-15947. https://doi.org/10.1039/c4cc07558g

Cheng C, Shen LD, Yu XF, Yang Y, Wang XF (2017) Robust construction of a graphene oxide barrier layer on a nanofibrous substrate assisted by the flexible poly(vinylalcohol) for efficient pervaporation desalination. J Mater Chem A 5:3558-3568. https://doi.org/ 10.1039/c6ta09443k 
Cho KM et al (2019) Ultrafast-selective nanofiltration of an hybrid membrane comprising laminated reduced graphene oxide/graphene oxide nanoribbons. ACS Appl Mater Interfaces 11:2700427010. https://doi.org/10.1021/acsami.9b09037

Cui KJ, Li P, Zhang R, Cao B (2020) Preparation of pervaporation membranes by interfacial polymerization for acid wastewater purification. Chem Eng Res Des 156:171-179. https://doi.org/ 10.1016/j.cherd.2020.01.022

Dong LL, Li MH, Zhang S, Si XJ, Bai YX, Zhang CF (2020) NH2$\mathrm{Fe} 3 \mathrm{O} 4-$ regulated graphene oxide membranes with well-defined laminar nanochannels for desalination of dye solutions. Desalination 476:114227. https://doi.org/10.1016/j.desal.2019.114227

Feng B, Xu K, Huang AS (2016) Covalent synthesis of three-dimensional graphene oxide framework (GOF) membrane for seawater desalination. Desalination 394:123-130. https://doi.org/10.1016/j. desal.2016.04.030

Gao Y, Su KM, Wang XT, Li ZH (2019) A metal-nano GO frameworks/PPS membrane with super water flux and high dyes interception. J Membr Sci 574:55-64. https://doi.org/10.1016/j.memsci.2018.12.052

García V, Pongrácz E, Phillips PS, Keiski RL (2013) From waste treatment to resource efficiency in the chemical industry: recovery of organic solvents from waters containing electrolytes by pervaporation. J Clean Prod 39:146-153. https://doi.org/10.1016/j.jclep ro.2012.08.020

Guo J, Bao HF, Zhang YQ, Shen X, Kim JK, Ma J, Shao L (2021) Unravelling intercalation-regulated nanoconfinement for durably ultrafast sieving graphene oxide membranes. J Membr Sci. https:// doi.org/10.1016/j.memsci.2020.118791

Halakoo E, Feng XS (2020) Layer-by-layer assembly of polyethylenimine/graphene oxide membranes for desalination of high-salinity water via pervaporation. Sep Purif Technol 234:116077. https:// doi.org/10.1016/j.seppur.2019.116077

Hung WS et al (2014) Cross-linking with diamine monomers to prepare composite graphene oxide-framework membranes with varying d-spacing. Chem Mater 26:2983-2990. https://doi.org/10.1021/ cm5007873

Jia ZQ, Wang Y, Shi WX, Wang JL (2016) Diamines cross-linked graphene oxide free-standing membranes for ion dialysis separation. J Membr Sci 520:139-144. https://doi.org/10.1016/j.memsci. 2016.07.042

Kim S et al (2018) Removal of contaminants of emerging concern by membranes in water and wastewater: a review. Chem Eng J 335:896-914. https://doi.org/10.1016/j.cej.2017.11.044

Kujawa J, Cerneaux S, Kujawski W (2015) Highly hydrophobic ceramic membranes applied to the removal of volatile organic compounds in pervaporation. Chem Eng J 260:43-54. https://doi. org/10.1016/j.cej.2014.08.092

Li D, Yao J, Sun H, Liu B, Li DY, van Agtmaal S, Feng CH (2018) Preparation and characterization of $\mathrm{SiO} 2 / \mathrm{PDMS} / \mathrm{PVDF}$ composite membrane for phenols recovery from coal gasification wastewater in pervaporation. Chem Eng Res Des 132:424-435. https://doi. org/10.1016/j.cherd.2018.01.045

Lin CH, Chen WH (2021) Influence of water, H2O2, H2SO4, and $\mathrm{NaOH}$ filtration on the surface characteristics of a graphene oxideiron (GO-Fe) membrane. Sep Purif Technol 262:118317. https:// doi.org/10.1016/j.seppur.2021.118317

Liu SY, Hu KW, Cerruti M, Barthelat F (2020) Ultra-stiff graphene oxide paper prepared by directed-flow vacuum filtration. Carbon 158:426-434. https://doi.org/10.1016/j.carbon.2019.11.007

Liu HQ, Xia JZ, Cui KJ, Meng JQ, Zhang R, Cao B, Li P (2021) Fabrication of high-performance pervaporation membrane for sulfuric acid recovery via interfacial polymerization. J Membr Sci 624:119108. https://doi.org/10.1016/j.memsci.2021.119108
Mei X et al (2020) A novel system for zero-discharge treatment of high-salinity acetonitrile-containing wastewater: combination of pervaporation with a membrane-aerated bioreactor. Chem Eng $\mathrm{J}$ 384:123338. https://doi.org/10.1016/j.cej.2019.123338

Nigiz FU (2019) Preparation and performance of ultra-thin surface coated pervaporation membranes for seawater purification. Water Supply 19:1778-1784. https://doi.org/10.2166/ws.2019.053

Oehmen A, Vergel D, Fradinho J, Reis MA, Crespo JG, Velizarov $S$ (2014) Mercury removal from water streams through the ion exchange membrane bioreactor concept. J Hazard Mater 264:6570. https://doi.org/10.1016/j.jhazmat.2013.10.067

Ong YK, Shi GM, Le NL, Tang YP, Zuo J, Nunes SP, Chung TS (2016) Recent membrane development for pervaporation processes. Prog Polym Sci 57:1-31. https://doi.org/10.1016/j.progpolymsci.2016. 02.003

Pan FS et al (2020) Graphene oxide membranes with fixed interlayer distance via dual crosslinkers for efficient liquid molecular separations. J Membr Sci 595:117486. https://doi.org/10.1016/j.memsci. 2019.117486

Park S, Dikin DA, Nguyen ST, Ruoff RS (2009) Graphene oxide sheets chemically cross-linked by polyallylamine. J Phys Chem C 113:15801-15804. https://doi.org/10.1021/jp907613s

Park S, Lee KS, Bozoklu G, Cai W, Nguyen ST, Ruoff RS (2008) Graphene oxide papers modified by divalent ions-enhancing mechanical properties via chemical cross-linking. ACS Nano 2:572-578. https://doi.org/10.1021/nn700349a

Pendergast MM, Hoek EMV (2011) A review of water treatment membrane nanotechnologies. Energy Environ Sci 4:1946-1971. https:// doi.org/10.1039/c0ee00541j

Qian YL, Zhou C, Huang AS (2018) Cross-linking modification with diamine monomers to enhance desalination performance of graphene oxide membranes. Carbon 136:28-37. https://doi.org/10. 1016/j.carbon.2018.04.062

Samsami S, Mohamadi M, Sarrafzadeh MH, Rene ER, Firoozbahr M (2020) Recent advances in the treatment of dye-containing wastewater from textile industries: overview and perspectives. Process Saf Environ Prot 143:138-163. https://doi.org/10.1016/j.psep. 2020.05.034

Shi B et al (2019) Control of edge/in-plane interactions toward robust, highly proton conductive graphene oxide membranes. ACS Nano 13:10366-10375. https://doi.org/10.1021/acsnano.9b04156

Sun JW, Qian XW, Wang ZH, Zeng FX, Bai HC, Li N (2020) Tailoring the microstructure of poly(vinyl alcohol)-intercalated graphene oxide membranes for enhanced desalination performance of highsalinity water by pervaporation. J Membr Sci 599:117838. https:// doi.org/10.1016/j.memsci.2020.117838

Suri A, Calzavarini L, Strunck AB, Magnacca G, Boffa V (2019) Comparison of chemical cross-linkers with branched and linear molecular structures for stabilization of graphene oxide membranes and their performance in ethanol dehydration. Ind Eng Chem Res 58:18788-18797. https://doi.org/10.1021/acs.iecr.9b01532

Tian Y, Cao Y, Wang Y, Yang W, Feng J (2013) Realizing ultrahigh modulus and high strength of macroscopic graphene oxide papers through crosslinking of mussel-inspired polymers. Adv Mater 25:2980-2983. https://doi.org/10.1002/adma.201300118

Toth AJ, Mizsey P (2015) Methanol removal from aqueous mixture with organophilic pervaporation: experiments and modelling. Chem Eng Res Des 98:123-135. https://doi.org/10.1016/j.cherd. 2015.04.031

Wang SF et al (2016b) A highly permeable graphene oxide membrane with fast and selective transport nanochannels for efficient carbon capture. Energy Environ Sci 9:3107-3112. https://doi.org/ 10.1039/c6ee01984f 
Wang QZ, Li N, Bolto B, Hoang M, Xie ZL (2016a) Desalination by pervaporation: a review. Desalination 387:46-60. https://doi.org/ 10.1016/j.desal.2016.02.036

Wang Y, Mei X, Ma TF, Xue CJ, Wu MD, Ji M, Li YG (2018) Green recovery of hazardous acetonitrile from high-salt chemical wastewater by pervaporation. J Clean Prod 197:742-749. https://doi. org/10.1016/j.jclepro.2018.06.239

Wang YJ, Tian Y, Zang WC, Jian XD (2016c) Study on treatment and recycling of mercury from waste mercury catalysts in China. Procedia Environ Sci 31:432-439. https://doi.org/10.1016/j.proenv. 2016.02.090

Wei Y, Zhang YS, Gao XL, Ma Z, Wang XJ, Gao CJ (2018) Multilayered graphene oxide membranes for water treatment: a review. Carbon 139:964-981. https://doi.org/10.1016/j.carbon.2018.07. 040

Wu XM, Zhang QG, Soyekwo F, Liu QL, Zhu AM (2016) Pervaporation removal of volatile organic compounds from aqueous solutions using the highly permeable PIM-1 membrane. AIChE J 62:842-851. https://doi.org/10.1002/aic.15077

Xi YH, Hu JQ, Liu Z, Xie R, Ju XJ, Wang W, Chu LY (2016) Graphene oxide membranes with strong stability in aqueous solutions and controllable lamellar spacing. ACS Appl Mater Interfaces 8:15557-15566. https://doi.org/10.1021/acsami.6b00928

Yang X et al (2014) A pervaporation study of ammonia solutions using molecular sieve silica membranes. Membranes (basel) 4:40-54. https://doi.org/10.3390/membranes4010040

Yang G et al (2019) Functionalizing graphene oxide framework membranes with sulfonic acid groups for superior aqueous mixture separation. J Mater Chem A 7:19682-19690. https://doi.org/10. 1039/c9ta04031e

Yi SL, Wan YH (2017) Volatile organic compounds (VOCs) recovery from aqueous solutions via pervaporation with vinyltriethoxysilane-grafted-silicalite-1/polydimethylsiloxane mixed matrix membrane. Chem Eng J 313:1639-1646. https:// doi.org/10.1016/j.cej.2016.11.061

Yu WZ, Yu TY, Graham N (2017) Development of a stable cation modified graphene oxide membrane for water treatment. 2d Materials 4:045006. https://doi.org/10.1088/2053-1583/aa814c

Yu JG, Yue BY, Wu XW, Liu Q, Jiao FP, Jiang XY, Chen XQ (2016) Removal of mercury by adsorption: a review. Environ Sci Pollut Res Int 23:5056-5076. https://doi.org/10.1007/ s11356-015-5880-x

Zhang YL, Benes NE, Lammertink RGH (2016) Performance study of pervaporation in a microfluidic system for the removal of acetone from water. Chem Eng J 284:1342-1347. https://doi.org/10. 1016/j.cej.2015.09.084

Zhang M, Mao Y, Liu G, Liu G, Fan Y, Jin W (2020) Molecular bridges stabilize graphene oxide membranes in water. Angew Chem Int Ed Engl 59:1689-1695. https://doi.org/10.1002/anie.201913010

Zhang Y, Zhang S, Chung TS (2015) Nanometric graphene oxide framework membranes with enhanced heavy metal removal via nanofiltration. Environ Sci Technol 49:10235-10242. https://doi. org/10.1021/acs.est.5b02086

Zhao W, Shi BL (2009) Removal of volatile organic compounds from water by pervaporation using polyetherimide-polyethersulfone blend hollow fiber membranes. Sep Sci Technol 44:1737-1752. https://doi.org/10.1080/01496390902775851

Publisher's Note Springer Nature remains neutral with regard to jurisdictional claims in published maps and institutional affiliations. 